\title{
The Experiences of Foundation Phase Teachers in Implementing the Curriculum
}

\author{
Nomvuyiso Theorin Makeleni \\ Department of Education: Eastern Cape Province \\ University of South Africa (UNISA), PO Box 392 Pretoria 0003 \\ nomvuyisom@vodamail.co.za \\ Mantsose Jane Sethusha \\ Department of Early Childhood Education, \\ University of South Africa (UNISA), PO Box 392 Pretoria 0003 \\ sethumj@unisa.ac.za
}

\section{Doi:10.5901/mjss.2014.v5n2p103}

\section{Abstract}

This article seeks to explore experiences of foundation phase teachers in rural schools with regard to curriculum implementation and how their knowledge and experiences influence the implementation of the curriculum. The research was conducted in the District of Lusikisiki in the Eastern Cape Province of South Africa. A qualitative case study research design was adopted and semi-structured interviews, classroom observations, and document analysis were also employed. The findings highlighted that, although teachers experienced challenges in curriculum implementation, they also acknowledged the benefits of previous curriculum workshops. This article recommends that, for teachers to implement curriculum effectively, the Department of Basic Education and the curriculum designers need to consider the context in which the curriculum has to be delivered. Amongst all other requirements for curriculum implementation, teachers have to be constantly monitored and supported to enhance the quality of teaching and learning.

Keywords: Curriculum implementation; foundation phase; teacher knowledge; teachers' experiences; National Curriculum Statement

\section{Introduction}

In recent years, foundation phase teachers in South Africa have been experiencing rapid curriculum changes influenced by the rapid increase in global knowledge, technology and skills. Currently, South Africa is reshaping its curriculum to meet the international standards of education. In 2002, the national Department of Education (DoE) introduced the National Curriculum Statement for Grades R-9 and Grades 10-12 (DoE: 2002). In 2005 foundation phase teachers began to implement the NCS, although they were still unsure of what was expected of them in terms of the curriculum changes due to lack of in-depth training and the uncertainty of planners and trainers themselves (Burger, 2010). On-going implementation challenges led to another curriculum review in 2009 and a single document known as the National Curriculum Statement Grades R-12 was introduced in 2011 (DBE, 2011a). According to DBE (2011a), the NCS document was meant to build on the previous curriculum but amended to provide clear specification of what needed to be taught and learnt on a term basis. The NCS represents the Curriculum and Assessment Policy Statement (CAPS) for teaching and learning in South African schools. This study began when teachers were introduced to CAPS, which is NCS in principle. Erden (2010:3) argues that if teachers do not comprehend what the curriculum theoretical framework is all about, they will fail to implement the curriculum successfully. It is against this background that this article explored the nature and extent to which foundation phase teachers' knowledge and understanding meet the requirements of curriculum implementation in their teaching contexts.

\section{Literature Review}

Teachers' experiences were explored on the components that are required for curriculum implementation which include training, curriculum principles, instructional planning, teaching and learning, and assessment. 


\subsection{Training teachers received for curriculum implementation}

Teachers require training in order to implement curriculum effectively. Recent investigation of curriculum implementation in rural primary schools in the foundation phase has revealed that teachers experience numerous challenges regarding teaching and learner achievement internationally and nationally (Fleisch, 2008; Moalosi \& Molwane, 2010:29). These challenges emanate from lack of effective teaching and learning of Mathematics and Literacy in the foundation phase. According to Mohd Meerah, Halim, Rahman, Abdullah, Hassan and Ismail (2010:50), to ensure the effective implementation of curriculum, teachers need to be well trained, highly motivated, dedicated and professionally competent.

In order to explore the nature of teachers' knowledge and understanding of the curriculum, it is necessary to evaluate the training programmes they received for implementing the curriculum, which are in the form of workshops. Ngware, Abuya, Mutisya and Oketch (2010) noted the success of planned in-service training in Malawi and Madagascar, arguing that good performance depends on carefully planned programmes. Similarly, Bennel (2010) highlights the positive outcomes of planned in-service training programmes and acknowledged that teachers in Malawi and Madagascar received appropriate curriculum training. The findings of Bennel's (2011) research highlight that teaching and learning had improved in Malawi and Madagascar, implying that well-planned curriculum guidance and support had a positive influence on teachers' knowledge and experiences in teaching practices.

In contrast, research by Moalosi and Molwane (2010:33) into the challenges facing teachers in teaching design and technology in lower primary schools in Botswana revealed that teachers received little training when the new curriculum was introduced. Teachers lacked in-service training to empower them for curriculum implementation and this led them to teach only components of the curriculum which they felt comfortable with. This shows that teachers' understanding and experiences has a significant influence on teaching practice. The literature in South Africa reveals that poorly planned workshops left teachers confused as to where, what and how to start teaching the curriculum (Lombard, Meyer, Warnich and Wolhutter, 2010:165; Maphalala, 2006:67; Matshidiso, 2007:109). The research findings also revealed that the training teachers received was initial training and merely provided background information and guidelines on lesson preparation. Sithole (2009) noted a slow development in implementing the curriculum in rural foundation phase classrooms. In a study conducted about organising knowledge for the classroom (Jansen, 2009:100) it was revealed that foundation phase teachers lacked content knowledge to teach Mathematics and knew very little about phonics in Literacy. It is therefore evident that teachers are experiencing various challenges resulting from the quality of training they receive.

\subsection{Knowledge and understanding of curriculum implementation}

The principles guiding the implementation of the curriculum are important for teachers to know and understand for effective teaching and learning. Oliver (2009:22) defines principles as guidelines that promote aims and objectives of the official curriculum. According to Lombard et al. (2010:5) and Mbingo (2006:15), the following are some of the guiding principles adopted by the Department of Education that teachers have to consider when planning teaching and learning; social justice; a healthy environment; human rights and inclusivity; high level of skills and knowledge; clarity and accessibility; progression and integration and assessment. Lombard et al. (2010:272) maintain that teachers lack clarity on how these principles are manifested in teaching and learning.

\subsection{Instructional planning teachers experienced}

Brown and Gordon (2009:26) mentioned planning as an important guide to one's daily activities and commitment, and to help the teacher in choosing goals which involve subject area, objectives to be achieved, skills to be developed, teaching approaches or methods, assessment, timeframes and the kind of learner that teachers need to develop. In a study on the National Curriculum Review, teachers highlighted that planning requirements had become unevenly complicated, and appeared to make little contribution to improving teaching and learning (DoE, 2009:25). In her research into teachers' experiences in teaching First Additional Language in rural primary schools, Nsamba (2009:35) found lack of proper planning for lessons, and that although teachers knew the stages of planning they found planning to be a difficult task. Since planning is usually the responsibility of the teacher, this research sought to explore how the foundation phase teachers' understanding and experiences meet the requirements of curriculum planning to support learners in developing skills, knowledge, and values that can be demonstrated across other curricular fields. 


\subsection{Teaching and learning}

Sigthorsson (2008:52) highlighted the importance of teachers' experience in curriculum practice. This is referred to teaching and learning of the subject content, language of instruction and the resources in the classroom environment. Sargent (2010:26) also investigated whether there was evidence of a relationship between national curriculum reform and patterns of social classroom interaction in rural primary schools in Northwest China. The findings indicated that teachers who used the new curriculum materials taught less, praised more, and emphasised the development of learners' self-expression and thinking abilities (Sargent, 2010:26). In his view, knowledge could be acquired through practice. On the other hand, Mohd Meerah et al (2010:28) explored teachers' experiences in teaching marginalised children in Malaysia and provided evidence that teachers in schools serving socially disadvantaged rural children reported lower levels of pupil motivation. Teachers preferred to explain to their learners the concepts and phenomena from the textbooks rather than asking them to explore the issues on their own.

Mohd Meerah et al. (2010:55) also reported that teachers were unaware of alternative approaches, and had no confidence in using inquiry-based teaching methods in their classroom practices. These studies reveal that teachers preferred to use traditional teaching methods based on a teacher-centred approach. Peat (2009:105) concurred that South African teachers in rural schools were struggling to use multiple teaching strategies that demand creativity in Arts and Culture, as they were not commonly exposed to them. Research in the foundation phase showed that learners were not ready to pursue more challenging activities (Jansen, 2009:138), and teaching and learning in rural areas was at an extremely low level of achievement (Fleisch, 2008:143).

Erden (2010) pointed to ineffective teaching methods and weak subject knowledge as contributing to poor quality teaching and learning. Amongst recent literature that has acknowledged a lack of quality teaching and learning in Mathematics and in Language in the foundation phase, Eloff, Louw and Wium (2010:14) conducted a study on Speech Language Therapists Support to Foundation Phase teachers with Literacy and Numeracy in rural and urban settings. The study aimed at supporting foundation phase teachers to facilitate listening and language skills effectively, but the results indicated a need for pre-training procedures and support that is more effective.

Fleisch (2008:143) noted that teachers in disadvantaged schools tend to have lower expectations of what learners can achieve and therefore tend to interpret the official curriculum to support their lower expectations. These claims were supported by Pinar (2010:92), who highlighted that South African learners from a disadvantaged background do not have access to the hierarchical level necessary to perform activities demanding higher order thinking,

Foundation phase teachers experience challenges with regard to the language of teaching and learning. Hoon, Rahman and Sigh (2010:68), stated in their study that $60 \%$ of teachers in Malaysia were dissatisfied with the use of English as the medium of instruction. The interviewed teachers accepted that they were supportive of the implementation of teaching Mathematics and Literacy in English in rural primary schools. On the other hand, they revealed that they were still struggling with challenges such as weak linguistics at schools, learners' inability to use English language and teachers' lack of English language background. The language policy in South African public schools emphasises that foundation phase learners need to be taught in their home language (DBE, 2011a: 8). Most teachers also believe that learners do well when they are taught in their home language. According to the Department of Education (2009:41), teachers in the foundation phase experience confusion in introducing English as the second language in the classroom situation. Nsamba (2009:27) argues that late introduction of English in the foundation phase affects learner performance negatively in the intermediate phase as English is used as a medium of instruction.

Ndamba's (2008) study of mother tongue use in learning and language preference in Zimbabwe revealed that parents in countries such as South Africa, Zimbabwe and Namibia resist mother tongue education in favour of English (Ndamba, 2008:173-175). Learning in Grade 4 often showed long term poor academic performance than learners continuing learning in their mother tongue, resulting in more learners with barriers to learning in their classrooms (Nel \& Theron, 2008:205). The above discussions reveal a gap between classroom teaching practices and language policy.

According to Brown and Gordon (2009), children learn better in classrooms that are well resourced and equipped with developmentally and age appropriate materials. A study by Glewwe, Kremer and Moulin (2007:11-45) criticized dependence on textbooks as the main resource, arguing that these failed to increase overall learner performance. Most disadvantaged South African schools do not have enough sets of textbooks and workbooks, and as a result they experience challenges in curriculum implementation. Teachers need to be well oriented on how to effectively use textbooks for effective teaching and learning. On the contrary, Abadzi (2006) defended the use of textbooks and claimed that their effectiveness depends on pedagogically sound, culturally appropriate and durable presentation. Countries such as Ghana, Philippines, Brazil, and Guinea had shown improvement in learner performance due to sufficient supply of 
textbooks, with textbook teaching, and learning resources working well and saving instructional time. However, Abadzi (2006) emphasised that teachers need training in the use of textbooks. In South African rural schools, teachers still experience a lack of textbook supply. Recently, the Minister of Basic Education in South Africa initiated a programme of workbooks from Grades 1 to 6 . This was meant to assist teachers to improve learner performance in Numeracy and Literacy in their classrooms. Generally teachers have limited resources at schools and do not know how to use them because of lack of training.

\subsection{Assessment}

Assessment is an intergral part of teaching and learning. Copple and Bredekamp (2009) define assessment as a tool for monitoring children's academic progress towards a programme-desired goal. Since the adoption and implementation of the National Curriculum Statement in South Africa, teachers have been experiencing challenges with classroom assessment. The National Protocol on Assessment (Department of Education: 2012) is aimed at providing a clear structure of how assessment should be conducted to ensure effective teaching and learning.

A study conducted by Nsamba (2009:76) revealed that teachers did not follow the assessment guidelines for English First Additional Language and therefore, learner performance in primary schools was affected. Kanjee, Molefe, Makgamatha, and Claassen (2010) conducted a similar study on teacher assessment practices in South African schools which was exploratory in nature and involved the use of classroom observations and interviews. The study found that teachers' knowledge and awareness of assessment practices were limited. The findings also revealed that there was a gap between teaching practices and the assessment policy application, which was created by lack of orientation programmes.

\section{Research Methodology}

This article presents research conducted in rural public primary schools in the Lusikisiki Central Circuit in the Eastern Cape, South Africa. Four foundation phase teachers were selected and semi-structured interviews, classroom observations and document analysis were used to explore their understanding and experiences of curriculum implementation. A case study was adopted to gain an in-depth understanding of teachers' experiences.

\section{Research Finding and Discussions}

This article reports on the empirical enquiry based on the main research question: "What are the experiences of Foundation Phase teachers regarding the implementation of the Curriculum?"

\subsection{Training teachers received}

The results of this study confirmed the research findings from other scholars, indicating that participants received little training when a curriculum was introduced (Moalosi \& Molwane, 2010: 33). Participants expressed the view that the training they received was inadequate for them to implement the curriculum effectively. In their responses, they indicated that the training they received was just providing a basic knowledge and understanding of the amendment to the curriculum, as one participant shared her experience:

"I thought that facilitators' knowledge and understanding on training teachers had been influenced by the fact that CAPS is built on NCS. Therefore, they took for granted that they should not go deep into training teachers because they already know more about NCS content. It was just to orientate teachers with the new additions and omissions."

On the other hand, there were teachers who benefited on CAPS training through the knowledge they gained from NCS previous workshops. Another participant responded as follows:

"CAPS training advanced me more because of the knowledge and understanding I received from NCS previous workshops."

Regarding the quality of training teachers received, the above responses reveal that teachers have different perceptions of the training they received. The findings further suggest that workshops have been provided before the 
curriculum implementation process could begin.

\subsection{Knowledge and understanding of curriculum principles}

Research has established that the majority of teachers in South African schools are not clear on how curriculum principles are applied (Harber \& Mncube, 2010). This study revealed evidence that some teachers were unfamiliar with curriculum principles in practice and experienced a challenge of infusing these curriculum principles in planning. Lesson observations and document analysis revealed that some teachers did not comply with curriculum principles, as they were unable to carry out assessment forms to the prescribed standard of National Protocol for Assessment (DoE: 2011) to enhance higher order knowledge and skills. Not all participants had intensive knowledge and understanding of the purpose of curriculum principles for curriculum implementation.

We discovered during document analysis that teachers had no record of programmes for supporting learners with barriers to learning in their portfolio files. Seemingly, they did not have intensive knowledge and understanding of the purpose of curriculum principles in teaching and learning practices.

\subsection{Instructional planning teachers experienced}

Our findings indicate that inadequate knowledge and understanding of curriculum principles also affected the value of instructional planning. Document analysis revealed that none of the four participants had proper planning for the lessons. One participant reflected as follows;

\footnotetext{
"I teach according to what is indicated in the CAPS document. Everything is prescribed; the content, knowledge, skills are all outlined per term and per grade. In this document, the curriculum designers already did other planning levels for us."
}

Another participant responded to "planning" as follows;

"Really...I see no need for lesson plans because the activities, resources, and assessment tasks for the term are indicated in CAPS document."

It is apparent from the above reflections that some teachers rely solely on what is prescribed, without even attempting to adapt activities according to their different contexts. The CAPS (2012) document requires that teachers examine suitability of themes and topics based on their contexts.

\subsection{Teaching and learning strategies}

Teachers' experiences in the classroom involved teaching and learning strategies, language of instruction, and the use of relevant resources. Participants had different learning tasks in their learners' classwork books, but the quality of work was below the standards prescribed in the curriculum documents. The curriculum encourages activities that promote higher order thinking, for example, interpretation of picture stories, answering various types of questions, including comprehension questions, and reading and writing. Activities based on creative writing were few and in some grades were not presented at all. The study found that all the four participants followed principles of the language policy, as they taught isiXhosa, Mathematics and Life-Skills in home language. Teachers reported that learners' performance had improved since they started teaching in the learners' home language. The findings supports the view of Eloff, Louw, and Wium (2010) that learners achieve better when taught in their mother tongue.

On the contrary, some participants were not comfortable teaching Mathematics in home language, especially in Grade Three, as they wanted to prepare learners for Grade Four, where the language of teaching and learning is English. Teachers in this research confirmed that school enrolment dropped in most public schools because of the use of home language as a medium of instruction. Participants believed that most parents moved their children to private schools where the medium of instruction is English.

\subsection{Assessment}

This study revealed that teachers still have a gap in understanding how to design formal assessment tasks according to 
curriculum assessment guidelines. Although participants had tried to cover the syllabi, the formal assessment tasks were not at the standard aligned with the requirements of National Curriculum Statement and the National Protocol for Assessment (DoE:2011). This implied that teachers were still battling with the interpretation of these documents.

Evidence gleaned from this study revealed that among all the challenges experienced by foundation phase teachers, unconducive infrastructure was highlighted as a factor that hindered the effective implementation of the curriculum. In the schools selected for this research, classroom walls were unfavourable for pasting wall charts, shortage of furniture was evident, and learners were seated in groups of three on one bench of two. The study revealed that teachers' experiences had influenced teaching and learning in that the academic results showed a greater number of learners falling below 50\%. In this study, all the participants were teaching more than 40 learners in class. We noted during the observations that the teacher-pupil ratio could contribute to the low performance of learners, as all four classes were overcrowded. It is against this background that we infer that teachers could not attend to learners individually and could not effectively assist those learners who experienced barriers to learning.

\section{Conclusion}

During the investigation of teachers' experiences on curriculum implementation, factors emerged that impede their curriculum implementation. This study highlighted the basic training teachers received, lack of curriculum interpretation, inadequate resources, poor infrastructure and overcrowding. According to the research findings, the basic training affected teachers' knowledge and understanding of curriculum principles, instructional planning, teaching and learning, and assessment practices in that some teachers were unable to meet the requirements of curriculum implementation. The study confirmed that teachers' knowledge and understanding of the basic requirements of curriculum implementation are not on the same level. The challenges highlighted above seemed likely to bring about curriculum implementation to an ultimate low level of success in some foundation phase classrooms. We conclude that some participants saw the implementation of curriculum for meaningful educational change as it provides learners with meaningful knowledge and skills for life. We recommend that curriculum designers consider the context in which the curriculum is to be implemented before the initial stage of curriculum implementation begins. More importantly, implementers of curriculum need to be evaluated by exploring their views through district Teacher Curriculum Development Forums, to ensure that they are ready to implement the curriculum changes. This will attempt to bridge the gap that may exist between theory and practice.

\section{References}

Abadzi, H. 2006. Efficient learning for the poor Insights from the frontier of cognitive neuroscience. Washington: World Bank.

Bennell, P. 2010. A UPE 15 Emergency programme for primary school teachers. Background paper for EFA Global Monitoring Report 2012. United Nations Educational, Scientific, and Cultural Organization. ENESCO.org. March 2011.

Brown, K.W. \& Gordon, A.M. 2009. To teach well: childhood practical guide. USA: Pearson Merrill.

Burger, D. 2009. Pocket Guide to South African Government communication and information System. http://www.info.gov.za. laboutsa/education. Date of access date:5 July 2010.

Copple, C. \& Bredekamp, S. (Eds). 2009. Developmentally appropriate practice in early childhood programmes. Washington, DC: NAEYC.

Department of Basic Education. 2011a. National Curriculum Statement: Curriculum and Assessment Policy Statement Foundation Phase Grade R-3. English First Additional Language. South Africa. Government Printer.

Department of Basic Education. 2011b. National Curriculum Statement: National Policy Pertaining to Programmed and Promotion Requirements of the National Curriculum Statement Grade R-12. South Africa: Government Printer.

Department of Basic Education. 2009. Report of the Task Team for the Review of the Implementation of National Curriculum Statement: Final Report. Pretoria: Government printer.

Department of Education, (2011). National Protocol for Assessment Grades R-12, Pretoria, South Africa.

Department of Education, (2011). National Curriculum Statement (NCS). Curriculum and Assessment Policy Statement (CAPS), English Home Language, Intermediate Phase, Grades 4-6, Pretoria, South Africa.

Eloff, I., Louw, B. \& Wium, A. 2009. Speech Language Therapist Supporting Foundation Phase teachers with Literacy and Numeracy in rural and township context. Pretoria: University of Pretoria.

Erden, E. 2010. Problems that preschool teachers face in the curriculum implementation. Dissertation-M.Ed. Middle East: Middle East Technical University.

Fleisch, B. 2008. Primary Education in Crisis: Why South African schools' children underachieve in reading and in Mathematics. Cape Town: Juta.

Glewwe, P., Kremer, M. \& Moulin, S. 2007. Many children left behind. Textbooks and test scores in Kenya. National Bureau of Economic 
Research. http://www.nber/papers/w13300.pdf. Date of access: August 2007.

Harber, C. \& Mncube, V. 2010. Chronicling educator practices and experiences in the contexts of democratic schooling and quality education in South Africa. International Journal of Education, 30(6): 614-624.

Hoon, T.S., Rahman, A.A. \& Sigh, P. 2010. Language and Mathematics achievement among rural and urban primary for pupils: Malaysian Experiences. Journal of Science and Mathematics, Education in South East Asia, 33 (1): 65-85.

Jansen, H. 2009. Curriculum: Organizing knowledge for the classroom. 2nd edition. South Africa: Oxford University Press.

Kanjee, A., Molefe, M.R.M., Makgamatha, M.M. \& Claassen, N.C.W. 2010. Teacher assessment practice in South African schools. Commissioned by the Department of Education. March. Abstract in MEDLINE.

Lombard, K., Meyer, L., Warnich, P. \& Wolhutter, C. 2010. Outcomes-Based Assessment for South African teachers. Pretoria: Van Schaik.

Moalosi, R. \& Molwane, O.B. 2010. Challenges facing teachers in teaching of design and technology in Botswana Primary schools: Design and Technology Education. An international Journal, 13(3).

Maphalala, M.C. 2006. Educator experiences in implementing the revised National Curriculum Statement in GET-Band. Thesis-PhD. Natal: University of Zululand.

Matshidiso, N.N.2007. Educators Perception of Outcomes Based Education Assessment. Dissertation- M.Ed. Potchefstroom: North West University.

Mbingo, S. J. 2006. Investigation into the implementation of the new curriculum by Foundation Phase teachers in Mpumalanga. Dissertation-M.ED. Johannesburg: University of Johannesburg.

Mohd Meerah, T.S., Halim, L., Rahman, S., Abdullah, R.T., Hassan, A., \& Ismail, A. 2010. Teaching Marginalized Children: Primary Science Teacher's Professional Development through Collaboration Action Research: Cypriot Journal of Educational Science, 2(2011): 49-60.

Ndamba, G.T. 2008. Mother Tongue Usage in Learning: An Examination of Language Preference in Zimbabwe. The Journal of Pan African Studies, 2(4). June 2008.

Nel, M. \& Theron, L. 2008. Language enrichment programme for Grade 4 ESL Learners with limited English proficiency. Paper presented at the AARE conference, November 2007. South Africa: North West University.

Ngware, M., Abuya, B., Mutisya, M. \& Oketch, M. 2010. Classroom Observation Study: A Report on the Quality Teaching and Learning in Primary Schools in Kenya. Nairobi: APHRC.

Nsamba, A.N. 2009. English language teaching in primary schools of Moshaweng Circuit in the Northern Cape. Dissertation-M.ED. Pretoria: University of South Africa.

Oliver, P.F. 2009. Developing the Curriculum. 7th edition. United States: Pearson Education.

Peat, E.M. 2009. Rural educators' implementation of the National Curriculum Statement Arts and Culture Learning Area: Educators' narratives. Dissertation. - M.ED. Natal: University of KwaZulu-Natal.

Pinar, F. 2010. Curriculum Studies in South Africa: Intellectual Histories and Present Circumstances. SA: Palgrave McMillan.

Sargent, T.C. 2009. Revolutionizing ritual interaction in the classroom: Constructing the Chinese Renaissance of the 21st century. Rutgers: The State University of New Jersey.

Sigthorsson, R. 2007. Teaching and learning in Icelandic and Science in context of national tests in Iceland: A conceptual model of curriculum teaching and learning. Iceland: Iceland University of Education.

Sithole, B. 2009. Investigating teachers' understanding of the principles and values of the Revised National Curriculum Statement (RNCS): A case study of the two township schools in Gauteng. Pretoria: HRSC. 
